Научная статья

УДК 341.221.2(510)

https://doi.org/10.24866/1813-3274/2021-3/182-199

\title{
ПОЗИЦИЯ КИТАЙСКОЙ НАРОДНОЙ РЕСПУБЛИКИ В ОТНОШЕНИИ ИСПОЛЬЗОВАНИЯ ТРАНСГРАНИЧНОЙ РЕКИ МЕКОНГ: МЕЖДУНАРОДНО-ПРАВОВОЙ АНАЛИЗ
}

Нгуен Тхи Ким Ань ${ }^{1}$, Российский университет дружбы народов (РУДН), Москва, Россия

E-mail: kimanh.nguyen281293@gmail.com

Аннотацุия. Бассейн реки Меконг и её притоков находится на полуострове Индокитай и объединяет территории шести государств. Меконг в своём верхнем течении (т.н. «Верхний Меконг») протекает по территории Китая (16\%) и Мьянмы $(2 \%)$, а в нижнем течении (т.н. «Нижний Меконг») - по территории Лаоса (35\%), Вьетнама (11\%), Камбоджи (18\%) и Таиланда (18\%). Соглашение по реке Меконг 1995 г. является единственным международным актом регионального характера, регулирующим совместное использование реки Меконг, в рамках которого учреждена Комиссия реки Меконг - главный международный институциональный механизм сотрудничества между прибрежными государствами. При этом только государства Нижнего Меконга сотрудничают в рамках многостороннего Соглашения 1995 г., а Китай и Мьянма предпочитают двухсторонние договоренности, что усложняет процесс координации по разным аспектам, таким как: производственная безопасность, доступ к чистой питьевой воде, экологическая безопасность, борьба с изменением климата, предотвращение и смягчение последствия стихийных бедствий и другие вопросы. Учитывая, что по территории Мьянмы протекает всего 2 \% Меконга, то наибольший интерес вызывает именно анализ позиции Китая, который как самый мощный игрок в регионе осуществляет собственную внешнюю политику под названием «мягкая дипломатия» по всем направлениям, включая водный сектор. Благодаря выгодному географическому положению Китай активно эксплуатирует реку Меконг и её ресурсы, строит ГЭС на главном течении и притоках. Опираясь на принцип суверенного права над всеми водными ресурсами на его территории, Китай старается решать все разногласия и противоречия с соседними государствами исключительно на основе двухсторонних переговоров без вмешательства третьих сторон. Вместе с тем нужно отметить, что в последние годы Ки-

\footnotetext{
${ }^{1}$ Нгуен Тхи Ким Ань, аспирант кафедры международного права, Российский университет дружбы народов (РУДН), Москва, Россия

. (C) Нгуен Тхи Ким Ань, 2021
} 
тай делает небольшие шаги для укрепления доверия и сотрудничества между государствами бассейна реки Меконг, так с Комиссией реки Меконг были заключены соглашения о предоставлении гидрологической информации, а также учреждены механизмы сотрудничества в бассейне Ланьцанцзян-Меконг. Следует отметить, что привлечение Китая к полному участию в общем международно-правовом режиме использования вод Меконга является критически важным. Всестороннее доверие может помочь устранить разногласия между всеми прибрежными государствами на основе взаимной выгоды и обмена информацией, что поможет обеспечить региональную безопасность и политическую стабильность в регионе.

Ключевые слова: трансграничная река Меконг, Соглашение по реке Меконг 1995 г., Комиссия реки Меконг, мягкая дипломатия, добрососедская дипломатия, Конвенция о праве несудоходных видов использования международных водотоков 1997 г., устойчивое развитие.

Для циитирования: Нгуен Тхи Ким Ань. Позиция Китайской Народной Республики в отношении использования трансграничной реки Меконг: международноправовой анализ // Азиатско-Тихоокеанский регион: экономика, политика, право. 2021. № 3. C. 182-199. https://doi.org/10.24866/1813-3274/2021-3/182-199.

Original article

\section{THE POSITION OF THE PEOPLE'S REPUBLIC OF CHINA REGARDING TRANSBOUNDARY MEKONG RIVER UTILIZATION: INTERNATIONAL LEGAL ANALYSIS}

Nguyen Thi Kim Anh ${ }^{1}$, Peoples' Friendship University of Russia (RUDN University), Russia

E-mail: kimanh.nguyen281293@gmail.com

Abstract. The Mekong River basin and its tributaries are located on the Indochina Peninsula and unites territories of six states. The upper Mekong reaches (so-called «Upper Mekong») flows through the territory of China (16\%) and Myanmar (2\%), and the lower reaches (so-called «Lower Mekong») - through the territory of Laos (35\%), Vietnam (11\%), Cambodia (18\%) and Thailand (18\%). The 1995 Mekong Agreement is sole multilateral regional act governing water sharing of the Mekong River, under which the Mekong River Commission was established - the main international institutional mechanism for cooperation between riparian states. At the same time, only four Lower Mekong states co-

\footnotetext{
${ }^{1}$ Nguyen Thi Kim Anh, Ph.D Student of Department of International law Peoples' Friendship University of Russia (RUDN University), Moscow, Russia.
} 
operate within the 1995 multilateral Agreement framework, while China and Myanmar prefer bilateral agreements, which complicates coordination process on various aspects, such as: industrial safety, access to clean drinking water, environmental safety, and the fight against climate changes, prevention and mitigation of natural disasters and other issues. Considering that only $2 \%$ of the Mekong flows through Myanmar's territory, analysis of China's water position, which, as the most powerful player in the region, carries out its own foreign policy called «soft diplomacy» in all areas, including the water sector, is of the greatest interest. Due to its favorable geographical position, China is actively exploiting Mekong River and its resources, building hydroelectric stations on the main stream and tributaries. Relying on the principle of sovereign right over all water resources on its territory, China is trying to resolve all disagreements and contradictions with neighboring states solely on the basis of bilateral negotiations without third parties' intervention. At the same time, it should be noted that in recent years, China has taken small steps to build trust and cooperation between Mekong states, so agreements on provision of hydrological information were concluded with the Mekong River Commission, and a mechanism for cooperation in the Lancangjiang-Mekong Basin was established. It should be noted that engaging China in full participation in general international legal regime for Mekong waters utilization is critically important. Comprehensive trust can help bridge differences between all riparian states on the basis of mutual benefit and information sharing, thus avoiding regional security and political stability in the region.

Keywords: transboundary Mekong River, 1995 Mekong River Agreement, Mekong River Commission, soft diplomacy, good neighbor diplomacy, 1997 Convention on the Law of the Non-Navigational Uses of International Watercourses, sustainable development.

For citing: Nguyen Thi Kim Anh. The position of the People's Republic of China regarding transboundary Mekong river utilization: international legal analysis // PACIFIC RIM: Economics, Politics, Law. 2021. No. 3. P. 182-199. https://doi.org/10.24866/18133274/2021-3/182-199.

Рассмотрим политику Китая в отношении трансграничных водотоков в целом, чтобы более детально разобраться, почему он дистанцируется от членства в международной Комиссии реки Меконг (далее - Комиссия), которая учреждена в рамках Соглашения о сотрудничестве по обеспечению устойчивого развития бассейна реки Меконг, подписанного Камбоджей, Лаосом, Таиландом и Вьетнамом в апреле 1995 г. в Чианграй [1].

В 1951 г. Китай присоединил Тибетский автономный район к своей государственной территории и тем самым создал условия для того, чтобы стать страной с богатыми водными ресурсами. Сегодня Китай занимает 6-е место среди государств с богатыми речными ресурсами, к которым относятся: Бразилия, Россия, Канада, США, Индонезия. Китай разделяет 42 трансграничных водотока (включая озёра) 
[2] с 17 государствами (с 14 из них имеет общие границы, а с 3 не имеет). Однако система рек в Китае распределяется неравномерно, средний объём воды на душу населения является в целом низким (121-е место в мире). Трансграничные водные отношения Китая характеризуются напряжённостью разного уровня.

Тибетский автономный район является истоком главных рек не только для Китая, но и для всей Южной Азии, там берут истоки реки Хуанхэ, Янцзы, Меконг, Салуин, Брахмапутра, Инд, которые впадают в Тихий и Индийский океаны [3, с. 121]. В большинстве случаев Китай находится в верхнем течении рек, что является основой для развития гидроэнергетики. Благодаря богатым водным ресурсам Китай занимает первое место в мире по количеству ГЭС и объёму вырабатываемой гидроэнергии (1302 ТВт/ч - по статистике 2019 г.) [4]. В бассейне реки Меконг Китай построил первую ГЭС Манван ещё в 1986 г., а в настоящее время Китай имеет 26 ГЭС на главном течении и 52 ГЭС на притоках Меконга, а также ещё запланированы 10 ГЭС на Меконге [5, с. 25]. Можно утверждать, что использование естественных ресурсов, в том числе водных, играет важную роль для развития экономики Китая.

В качестве государства, расположенного в верхнем течении многих трансграничных рек, Китай осуществляет собственную политику, максимально реализуя национальные интересы. Следовательно, Китай опирается на принцип государственного суверенитета над естественными ресурсами, находящимися на его территории. Китай предлагает решать подобные вопросы с прибрежными государствами исключительно в рамках двухсторонних переговоров, без вмешательства третьих лиц. Данный переговорный процесс называется «мягкой дипломатией», он представляет собой три ключевых элемента: концепция защиты национальных интересов, двухсторонние отношения, акцент только на процедурных и технических аспектах сотрудничества [6, с. 39]. Несмотря на большое количество трансграничных рек на его территории, Китай не является участником Конвенции о праве несудоходных видов использования международных водотоков 1997 г. (далее - Конвенция 1997 г.) [7]*. Более того, Китай является одним из трёх государств (вместе с Бурунди и Турцией), который голосовал против принятия проекта Конвенции 1997 г. [8, с. 99], которая сегодня определяет основные принципы, регулирующие совместное использование водных ресурсов прибрежными государствами, обязует государства справедливо и разумно использовать трансграничный водоток, не причинять значительный ущерб, обязует государства сотрудничать, а также выполнять разные процедурные правила по обмену данными и проведению консультаций. В частности, в Конвенции 1997 г. закреплены следующие принципы: справедливого и разумного использования и участия (ст. 5), обязательства не наносить значительный ущерб (ст. 7), общего обязательства сотрудничать (ст. 8). Китай представ-

\footnotetext{
* По данным на март 2021 г. Конвенцию ратифицировали 37 государств (Прим. авт.).
} 
ляет четыре причины, объясняющие его голосование «против» принятия текста Конвенции: 1) отсутствие общего согласия государств; 2) Конвенция не содержит ссылку на государственный суверенитет (в ст. 8 говорится, что «государства водотока сотрудничают на основе суверенного равенства» - т.е. акцент именно на равенстве); 3 ) наличие предполагаемого дисбаланса между государствами верховья и низовья по течению трансграничных рек; 4) неприятие обязательных механизмам урегулирования споров (ст. 33 Конвенции 1977 г. предполагает в т.ч. разрешение споров Комиссией по установлению фактов) [9, с. 395]. Попутно отметим относительно остальных двух государств, проголосовавших против принятия Конвенции: Республика Бурунди не дала подробного разъяснения своего голосования, а Турция, аналогично китайской позиции, выразила беспокойство в отношении спорных вопросов (принцип справедливого и разумного использования, принцип непричинения вреда, механизм разрешения споров обязательного характера) [10, с. 190].

На национальном уровне Китай детально разработал законодательство, регулирующее водные отношения (Закон об охране окружающей среды 1989 г. (пересмотрен в 2014 г.) [11], Лесной кодекс 1984 г. (с изменениями в 1998 г.) [12], Закон о сохранении воды и почвы 1991 г. [13], Закон о предотвращении и контроле загрязнения воды 1984 г. (с изменениями в 1996 г.) [14], Водный закон 1988 г. (пересмотрен в 2002 г.) [15] и др.). В законодательстве зафиксирован принцип: водные ресурсы находятся в собственности государства. В 2012 г. Китай разработал административный документ под названием «Мнения Государственного Совета КНР о применении строгой системы контроля водных ресурсов», который состоит из 5 разделов и 20 пунктов (т.н. «стратегия о трёх красных линиях»: контроль освоения и использования водных ресурсов; контроль эффективности водопользования; ограничение выбросов загрязняющих веществ в водные функциональные зоны») [16]. Целями принятия указанного документа являются: учреждение системы управления водными ресурсами; содействие рациональному развитию водных ресурсов; использование, сохранение и защита водных ресурсов и обеспечение устойчивого развития в Китае.

Стоит отметить, что экономика Китая очень быстро развивается, она вышла на второе мировое место после США. По количеству населения Китай занимает первое место в мире, и численность населения продолжает расти. Всё это увеличивает огромное давление на естественные ресурсы и экосистемы Китая, включая водную экосистему. Надо отметить, что нагрузка на речные ресурсы, включая трансграничные и внутренние, ложится огромная, поскольку они используются для достижения таких целей, как орошение, производственная и сельскохозяйственная деятельность, обеспечение безопасности питьевой воды и др. Разные исследования показывают, что от 30 до 70 \% рек в Китае являются серьезно загрязнёнными, некоторые реки больше не впадают в море, в результате чего значительно уменьшилось 
их биоразнообразие [3, с. 129]. Таким образом, водная политика Китая является крайне важной не только для обеспечения внутренней безопасности, но и для всего Азиатского региона, так как затрагиваются национальные интересы многих государств, разделяющих трансграничные водные ресурсы с Китаем. Это особенно важно, учитывая, что в Азии около 1,5 млрд людей живут вдоль бассейна трансграничных рек.

В соответствии с официальным документом Министерства по водным ресурсам, в Китае в настоящее время уровень использования водных и гидроэнергетических ресурсов трансграничных рек всего 8\% и 7\% соответственно, что намного ниже среднего показателя для внутренних рек в Китае, а также показателей крупных рек в других странах. Более того, Китай официально заявляет свою позицию: в первую очередь учитываются интересы жителей на основании равенства, затем баланс между экономическим развитием и экологической безопасностью, а затем хорошие отношения и координация с соседними государствами [17].

К настоящему времени Китай создал механизм по координации и сотрудничеству по поводу использования трансграничных водных ресурсов с соседними государствами в разных областях: обмен информацией для прогнозирования в сезон наводнений; борьба с наводнениями; аварийное реагирование; улучшение состояния пограничных рек; использование и охрана водных ресурсов и др. В основном Китай очень активно заключает только двухсторонние соглашения об обмене информацией и сборе данных, несмотря на то, что многие реки пересекают границы более чем двух государств. Китай имеет около пятидесяти соглашений по трансграничным водам [18]. В списке государств, с которыми Китай имеет соглашения, входят: Россия [19, с. 250], Северная Корея, Казахстан, Монголия, Мьянма, Лаос, Вьетнам, Индия, Афганистан, Бутан, Кыргызстан, Непал, Пакистан. Речь идёт прежде всего о заключении двухсторонних соглашений или меморандумов о взаимопонимании (MOUs), а также об участии Китая в региональных организациях или органах в качестве наблюдателя [20]. Подход «одно государство - одно соглашение» (one-country, one-treaty) является главным принципом осуществления политики «мягкой дипломатии» по урегулированию совместного использования трансграничных водотоков Китая [18].

Следует сказать, что правовая основа межгосударственного водопользования между Китаем и другими прибрежными государствами является недостаточной, особенно с государствами, расположенными к югу от Китая. К сожалению, практика показывает, что Китай в любой момент может отказаться от обязательств, закрепленных в меморандумах о взаимопонимании, которые, правда, относятся к документам «мягкого» права, в т.ч. из-за отсутствия механизма контроля и обязательных мер. В качестве примера можно привести Индию. Отношения между Китаем и Индией довольно напряжённые, они содержат определённый конфликтный потенциал. В це- 
лом, между двумя государствами достигнут ряд договорённостей, которые усиливают доверие и укрепляют индийско-китайское сотрудничество [21, с. 273]: Меморандум о взаимопонимании при предоставлении гидрологической информации по реке Ялузангбу-Брахмапутра в сезоне наводнения 2002 г. [22]; Меморандум о взаимопонимании между Министерством водных ресурсов Республики Индия и Министерством водных ресурсов Китайской Народной Республики по обмену гидрологическими данными по реке Сатледж-Лангкен-Зангбо 2010 г. [23]; Заявление об учреждении на экспертном уровне механизма взаимодействия и сотрудничества в сезон наводнений по обмену гидрологическими данными, совместному управлению в чрезвычайных ситуациях и другим проблемам трансграничных рек 2006 г. [24]; Меморандум о взаимопонимании между Министерством водных ресурсов Республики Индия и Министерством водных ресурсов Китайской Народной Республики об укреплении сотрудничества по трансграничным рекам 2013 г. [25].

Несмотря на это, в 2017 г. Китай нарушил обязательство передавать информацию для прогнозирования, когда отказался от передачи данных Индии [26]: Китай в качестве государства, расположенного в верхнем течении р. Брахмапутры, в одностороннем порядке изменил естественное состояние реки для построения ГЭС и создания искусственного озера. В последние годы стали активными принципиальные основы использования трансграничных вод в мировой практике в целом. При этом, справедливо ли когда только Китай обладает водными ресурсами Тибета, если реки, начинающиеся здесь, являются источником обеспечения водой многих азиатских стран [27]. Более того, Китай в 2021 г. заявил о строительстве самой крупной в мире ГЭС в тибетском регионе на р. Брахмапутра (в Китае она называется «р. Ярлунг-Цангпо») [28]. Отсутствие общепризнанного универсального договора по трансграничным водам с участием Китая, как главного игрока в регионе и в мире в целом, усложняет процесс проведения переговоров об общей политике, касающейся управления трансграничными реками.

Рассматривая водную политику Китая в отношении р. Меконг (китайское название «Ланьцанцзян» ${ }^{*}$ ), можно отметить следующие моменты. В 1990-х гг. Китай начинал активную эксплуатацию р. Меконг в целях рыболовства, орошения и построения ГЭС, это является главной причиной напряжённости отношений с государствами, расположенными ниже по течению реки (Вьетнам, Таиланд, Лаос и Камбоджа). Некоторые учёные и дипломаты сравнивают отношение Китая к использованию р. Меконг с отношением к Южно-Китайскому морю [29, с. 16], поскольку использование и распределение водных ресурсов затрагивают политические, экономические, социальные интересы и приводят к конфликтному состоянию заинтересованных сторон региона. Более того, государства бассейна Нижнего Ме-

\footnotetext{
* Ланьцанцзян - название реки Меконг на китайском языке, в остальных государствах используют название Меконг.
} 
конга являются наиболее уязвленными сторонами, поскольку процесс эксплуатации реки со стороны Китая непосредственно затрагивает их экономическое развитие и продовольственную безопасность в регионе [30, с. 192-193].

Помимо двухсторонних соглашений с отдельными прибрежными государствами бассейна реки Меконг с 1996 г. Китай официально вступил в диалог с Комиссией по реке Меконг в качестве т.н. «партнёра диалога». Причины неучастия Китая в Соглашении по реке Меконг 1995 г. и неприсоединения в качестве полноправного члена к Комиссии разнообразны. Во-первых, у Китая не существует особого интереса участвовать в региональном международном органе, который ограничивает его права как государства Верхнего Меконга, поскольку участие повлечёт наложение обязательств сообщать и обсуждать все планируемые проекты по течению реки. Во-вторых, как отмечено выше, Китай осуществляет собственную политику и предполагает заключать двухсторонние соглашения по регулированию совместного использования трансграничных водотоков. В-третьих, растущая экономика и прирост населения Китая увеличивает и без того огромную нагрузку на естественные ресурсы, в том числе и водные ресурсы. Китайское правительство должно запланировать долгосрочную стратегию по запасам пресной воды для удовлетворения своих потребностей. И, в-четвёртых, Китай является одной из самых мощных экономик в мире и постоянно оказывает своё влияние на другие государства. Путём «добрососедской дипломатии», которая является сочетанием традиционной дипломатии, экономической дипломатии [31, с. 13] и разных экономических инициатив, Китай укрепляет не только политическую, но и финансовую связь и координацию в регионе.

Следует отметить, что привлечение Китая к полному участию в общем международно-правовом режиме использования вод Меконга является критически важным, чтобы совершенствовать этот режим и укреплять сотрудничество. Всестороннее доверие может помочь устранить разногласия между всеми прибрежными государствами на основе взаимной выгоды и обмена информацией, что поможет избежать спорных ситуаций. Иными словами, только сотрудничество сможет обеспечить региональную безопасность, а также политическую стабильность. Укрепляемый международно-правовой режим использования вод Меконга способен регулировать совместное использование и обеспечить устойчивое развитие в регионе.

В качестве «партнёра диалога» с Комиссией Китай заключил Соглашение о предоставлении гидрологической информации реки Меконг в течение сезона наводнения с Комиссией по р. Меконг в 2002 г. (с изменениями в 2008 и 2013 гг.) [32]. В 2020 г. между Китаем и государствами Комиссии было подписано новое соглашение о предоставлении круглогодичной гидрологической информации реки Меконг [33] (к сожалению, тексты данных Соглашений не являются общедоступным). 
В целом существует явная нехватка данных, адекватных международноправовых и институциональных основ, способных регулировать совместное использование, управление и сохранение реки Меконг между Китаем и четырьмя государствами низовья [34, с. 240].

В 2012 г. Таиланд предлагал инициативу устойчивого развития в отношении использования Ланьцанцзян-Меконг, которая получила широкую поддержку со стороны китайского правительства. Китай в 2014 г. на 17-м Саммите Китай - АСЕАН предложил сформировать механизм сотрудничества Ланьцанцзян-Меконг (the Lancang-Mekong Cooperation Framework), при котором будет действовать Научноисследовательский центр (далее - МЛС). В 2016 г. шесть прибрежных государства бассейна реки Меконг подписали Декларацию Санья о сотрудничестве [35]. Координация будет проходить по трём направлениям: проблематика политики и безопасности; экономическое, культурно-социальное и устойчивое развитие; обмен информацией и техническими данными между шестью прибрежными государствами. Также в Декларации Санья 2016 г. было зафиксировано пять приоритетных областей сотрудничества: укрепление доверия; трансграничное экономическое сотрудничество; сельское хозяйство; сокращение бедности; управление водными ресурсами [36]. В соответствии с данной Декларацией были разработаны приоритетные сто проектов, которые заложили прочную основу для всестороннего и долгосрочного сотрудничества между государствами [37]. Например, Китай предоставил остальным государствам кредиты со специальной ставкой для развития инфраструктуры.

Рассматривая правовую основу деятельности механизма сотрудничества Ланьцанцзян-Меконг отметим следующее. В преамбуле Декларации Санья 2016 г. были закреплены следующие принципы: принцип консенсуса, принцип равенства, принцип консультаций и координации, добровольности, принцип общего вклада и общей взаимовыгоды, а также принцип соответствия Уставу ООН и международному праву. К сожалению, очень сложно обеспечивать осуществление перечисленных принципов на практике из-за наличия финансовых долгов перед Китаем, а также историко-геополитических напряженностей региона, которые до сих пор влияют на дипломатические отношения между государствами-членами. Более того, из шести прибрежных государств только Вьетнам ратифицировал Конвенцию о праве несудоходных видов использования международных водотоков 1997 г. - основный международный документ, регулирующий совместное использование международных вод. В механизме сотрудничества Ланьцанцзян-Меконг в основном отсутствует независимый характер - важнейший элемент международной организации, поскольку страны механизма учредили в Китае Центр сотрудничества с целью укрепления всестороннего сотрудничества по обмену техническими данными, борьбе с засухой и наводнениями, совместным исследованиям и другим аспектам, связанным с использованием водных ресурсов реки Меконг. 
Надо сказать, что в Декларации Санья 2016 г. не определены правовой статус и юридическая природа деятельности данного Центра сотрудничества, а также отсутствует механизм контроля выполнения обязательств [38]. Получается так, что Китай как наиболее экономически развитое государство обладает благоприятными условиями для руководства Центром, а также правами использования и распространения полученных данных.

В пятилетнем плане действий по сотрудничеству Ланьцанцзян-Меконг (20182022 гг.) [39] определены следующие направления сотрудничества: обмен данными, информацией и опытом в управлении трансграничными водными ресурсами по разным секторам, таким как адаптация к изменению климата, безопасность плотин, безопасность питьевой воды, борьба с наводнениями и засухами. Следует сказать, что принятие актов «мягкого» права по совместному управлению использованием водных ресурсов в бассейне реки Меконг создаёт предпосылки для укрепления доверия между государствами региона. Однако в целях усиления эффективности такого сотрудничества должны приниматься более конкретные положения не только по процедурным вопросам, но и оперативным секторам деятельности. Механизм контроля и обеспечения выполнения также крайне важен среди приоритетных направлений сотрудничества государств бассейна реки Меконг.

Касательно обмена данными и информацией ст. 7 Вьентьянской декларации 2020 г., принятой на третьей встрече лидеров механизма сотрудничества Меконг-Ланьцанцзян [40], установила следующее. Обмен гидрологической информацией играет важную роль для достижения устойчивого использования водных ресурсов на основе взаимной выгоды между прибрежными государствами, он будет осуществляться путём заключения Меморандума между Центром МЛС и Секретариатом Комиссии по р. Меконг. На встрече в 2020 г. «китайская сторона заявила, что, начиная с этого года, будет делиться со странами бассейна Меконга гидрологической информацией, с тем чтобы совместно создать платформу сотрудничества в области водных ресурсов. Это имеет большое значение для сельскохозяйственных регионов вдоль реки Меконг» [41].

Несмотря на геостратегические интересы и программу добрососедства с Таиландом и Вьетнамом, Китай является наиболее активным экономическим партнёром Лаоса по инвестициям в производство и строительство [42, с. 296]. Относительно использования реки Меконг со стороны Лаоса отметим, что с помощью китайского капитала он занимается различными видами экономической деятельности: развивает инфраструктуру, занимается гидроэнергетикой, речным хозяйством, водным транспортом, пищевой промышленностью и др.

Получается, что Китай, в качестве самого мощного прибрежного государства, усиливает своё экономическое влияние в каждом из прибрежных государств и потому играет важнейшую роль в управлении водными ресурсами реки Меконг и обеспечении её экологической безопасности [43, с. 1159]. 
В заключение можно сказать, что, несмотря на отказ от участия в международных договорах по совместному использованию трансграничных рек (глобального или регионального характера), Китай осуществляет собственную водную политику для регулирования совместного использования реки Меконг, предлагает некоторые инициативы сотрудничества между прибрежными государствами. Механизм сотрудничества Ланьцанцзян-Меконг за пять лет накопил немало положительного опыта в области сельского хозяйства, борьбы с бедностью, в использовании водных ресурсов; хотя он имеет различные недостатки, но продолжает играть важную роль в укреплении всесторонней координации в бассейне реки Меконг.

\section{Список литературы}

1. Agreement on the cooperation for the sustainable development of the Mekong River basin 5 April 1995. - URL: http://www.mrcmekong.org/assets/Publication s/agreements/95-agreement.pdf (дата обращения: 05.09.2021).

2. Svensson, J. China's water policy and the sharing of international rivers in Asia. - URL: http://www.globalwaterforum.org/2018/03/21/q-a-chinas-water-policy-andthe-sharing-of-international-rivers-in-asia/ (дата обращения: 05.05.2021).

3. Борисова, Е. А. Трансграничные реки в политике Китая // Восток = Orients. - 2015. - № 2. - C. 121-131.

4. International hydropower association. Country profile. China. - URL: https://ww w.hydropower.org/country-profiles/china\#: : text=According\%20to\%20IHA's\%202020 $\% 20$ Hydropower,at\%20up\%20to\%20600\%20GW (дата обращения: 05.05.2021).

5. Bokeriya, S. Hydropower development in Mekong River basin / S. Bokeriya, Nguyen Thi Ngoc Lan // Asia and Africa today. 2019. - № 10. - C. 24-29.

6. Рысбеков, Ю. Х. Управление водными ресурсами в Китае / Ю. Х. Рысбеков, А. Ю. Рысбеков. - Ташкент, 2014. - 80 с. - (Информационный сборник НИЦ МКВК; № 41).

7. Конвенция о праве несудоходных видов использования международных водотоков 1997 г. : принята резолюцией 51/229 Генеральной Ассамблеи от 21 мая 1997 г. - URL: https://www.un.org/ru/documents/decl_conv/conventions/watercrs.shtml (дата обращения: 05.05.2021).

8. Menniken, T. China's performance in international resource politics: lessons from the Mekong // Contemporary Southeast Asia. - 2007. - Vol. 1 (29). - P. 97-120.

9. Devlaeminck, D. J. China and global water conventions in light of recent development: Time to take a second look / D. J. Devlaeminck, Xisheng Huang // Review of European, comparative and environmental law. - 2020. - Vol. 29 (3). - P. 395-405.

10. Rieu-Clarke, A. Still not in force: should states support the 1997 UN Watercourses Convention? / A. Rieu-Clarke, F. R. Loures // Review of European Community \& International Environmental Law. - 2009. - Vol. 18 (2). - P. 185-197. 
11. Environmental protection law of the People's Republic of China. Adopted on December 26, 1989, revised on April 24, 2014. - URL: http://www.china.org.cn/english/ environment/34356.htm (дата обращения: 05.05.2021).

12. Forestry law of the People's Republic of China. Adopted on September 20, 1984, amended on April 29, 1998. - URL: http://www.china.org.cn/english/environm ent/207457.htm (дата обращения: 05.05.2021).

13. Law of the People's Republic of China on water and soil conservation. Adopted on June 29, 1991. - URL: http://www.china.org.cn/environment/200708/20/content_1034358.htm (дата обращения: 05.05.2021).

14. Law of the People's Republic of China on prevention and control water pollution. Adopted on May 11, 1984, amended on May 15, 1996. - URL: http://www.china.org.c n/government/laws/2007-04/17/content_1207459.htm (дата обращения: 05.05.2021).

15. Water law of the People's Republic of China. Adopted on January 21, 1998. URL: http://www.china.org.cn/english/government/207454.htm (дата обращения: 05.05.2021).

16. Ministry of Water Resources. Briefings on the opinions of the state council on implementing the strictest water resources management system. - URL: http://www.china.org.cn/china/2012-02/17/content_24664350.htm (дата обращения: 05.05.2021).

17. Ministry of Water Resources, People's Republic of China. International cooperation on trans-boundary rivers between China and its neighbouring countries 2015. URL: $\quad$ http://www.mwr.gov.cn/english/mainsubjects/201604/P020160406513798903 048.pdf (дата обращения: 05.05.2021).

18. Devlaeminck, D. J. China's water sharing treaties - Reciprocity in practice. China water risk. 2019. - URL: https://www.chinawaterrisk.org/opinions/chinas-watersharing-treaties-reciprocity-in-practice/ (дата обращения: 05.05.2021).

19. Солнцев, А. М. От конфликта к сотрудничеству: российско-китайские отношения в области управления водными ресурсами // Международное право = International Law. - 2009. - № 1. - C. 246-261.

20. Lei, Xie. China's international transboundary rivers: Politics, security and diplomacy of shared water resources / Lei Xie, Shaofeng Jia. - Routledge, 2017. 222 p. - DOI 4324/9781315537900.

21. Солнцев, А. М. Проблема использования трансграничных рек в странах БРИКС // Правовое регулирование охраны окружающей среды в странах БРИКС: монография / под ред. Е. Ф. Гладун, О. В. Захаровой, Е. А. Карагулян. - Тюмень : Изд-во Тюменского государственного университета, 2018. - С. 261-277.

22. Memorandum of Understanding between the Ministry of Water Resources, the Republic of India and the Ministry of Water Resources, the People's Republic of China 
upon Provision of Hydrological Information of the Yaluzangbu/Brahmaputra River in Flood Season by China to India. - URL: http://waterbeyondborders.net/wpcontent /uploads/2018/05/Indo-China-MOU-on-Brahmaputra.pdf (дата обращения: 05.09.2021).

23. Memorandum of Understanding on Hydrological Data Sharing on River Sutlej / Langqen Zangbo. - URL: https://jalshakti-dowr.gov.in/international-coopera tion/bilateral-cooperation-with-neighbouring-countries/india-china-cooperation (дата обращения: 05.09.2021).

24. India-China cooperation. - URL: http://mowr.gov.in/international-coopera tion/bilateral-cooperation-with-neighbouring-countries/india-china-cooperation (дата обращения: 05.05.2021).

25. Memorandum of Understanding between the Ministry of Water Resources, the Republic of India and the Ministry of Water Resources, the People's Republic of China on Strengthening Cooperation on Trans-border Rivers on October 23, 2013. - URL: https://mea.gov.in/bilateral-documents.htm?dtl/22368 (дата обращения: 05.05.2021).

26. Chellaney, B. China is stealthily waging a water war (January 12, 2018). URL: https://www.theglobeandmail.com/opinion/china-is-stealthily-waging-a-waterwar/article37583969/ (дата обращения: 05.05.2021).

27. Свинарчук, Т. О. Трансграничные реки Индии и Китая: проблемы совместного использования вод // Водные ресурсы Индии: экономические, политические, социальные аспекты : материалы научной конференции. - Москва : Институт востоковедения РАН, 2015. - С. 260-280.

28. Мамчиц, Р. В Тибете построят крупнейшую в мире ГЭС (Март 13, 2021). URL: www.if24.ru/v-tibete-postroyat-krupnejshuyu-v-mire-ges/ (дата обращения: 05.05.2021).

29. Zhang, Hongzhou. China and Transboundary water policies in Asia / Hongzhou Zhang, Mingjiang Li. - Routledge, 2019. - 242 p.

30. Kornfeld, I. Mega-dams and indigenous human rights / I. Kornfeld. - Cheltenham, UK ; Northampton, MA : Edward Elgar Publishing, 2020. - 244 p.

31. Лексютина, Я. «Добрососедская дипломатия» Китая в Восточной Азии // Азия и Африка сегодня. - 2017. - № 9. - С. 12-18.

32. MRC and China renew pact on water data provision and other cooperation initiatives. - URL: http://www.mrcmekong.org/news-and-events/news/mrc-and-china-renewpact-on-water-data-provision-and-other-cooperation-initiatives/ (дата обращения: 05.05.2021).

33. China to provide the Mekong River Commission with year-round water data. URL: https://www.mrcmekong.org/news-and-events/news/china-to-provide-the-mekongriver-commission-with-year-round-water-data/ (дата обращения: 05.05.2021).

34. Wouters, P. China's «soft-path» to transboundary water cooperation examined in the light of two UN Global water conventions - Exploring the «Chinese way» / P. Wouters, Huiping Chen // Water law. - 2013. - № 22. - P. 229-247. 
35. Sanya Declaration of the First Lancang-Mekong Cooperation (LMC) Leaders' Meeting. - URL: https://www.fmprc.gov.cn/mfa_eng/wjdt_665385/2649_665393/t 1350039.shtml (дата обращения: 05.05.2021).

36. Lancang-Mekong Cooperation: MRC welcomes the New Initiative for Regional Cooperation by six countries in the Mekong River Basin. - URL: http://www.mrcmekong.org/news-and-events/news/lancang-mekong-cooperation-mrcwelcomes-the-new-initiative-for-regional-cooperation-by-six-countries-in-the-mekongriver-basin/ (дата обращения: 05.05.2021).

37. Li Keqiang's address at the 1st Lancang-Mekong Cooperation Leaders' Meeting. - URL: http://www.lmcchina.org/eng/zywj_5/t1514128.htm (дата обращения: 05.05.2021).

38. Pham Phan Long. China's strategy on Lancang-Mekong Cooperation // Viet Ecology Foundation. April 2016. - URL: https://www.rfa.org/vietnamese/news/Readers Opinions/langcang-mekong-2016-pplong-04192016155259.html (дата обращения: 05.05.2021).

39. Five-year plan of action on Lancang-Mekong Cooperation (2018-2022), adopted on $4^{\text {th }}$ Lancang-Mekong cooperation mechanism foreign minister's meeting - «Enhancing partnership for shared prosperity» 12.2018. - URL: https://data.opendevelopment mekong.net/dataset/five-year-plan-of-action-on-lancang-mekong-cooperation-20182022/resource/2116a77e-e493-42dd-90cb-edce1d3693df? inner_span=True (дата обращения: 05.05.2021).

40. Vientiane Declaration of the Third Mekong-Lancang Cooperation (MLC) Leaders' Meeting 24.08.2020. - URL: http://www.lmcchina.org/eng/zywj_5/t1809002.htm (дата обращения: 05.05.2021).

41. Страны бассейна реки Меконг укрепляют партнерство. - URL: https://rg.ru/2020/08/26/strany-bassejna-reki-mekong-ukrepliaiut-partnerstvo.html (дата обращения: 05.05.2021).

42. Калинин, В. А. Экономические интересы китайского бизнеса в Лаосе: новые тенденции 2000-2010-х гг. / В. А. Калинин, А. А. Трошин, В. В. Балашов // Экономические отношения. - 2017. - № 3 (4). - С. 296-304.

43. Review: China's transboundary waters: new paradigms for water and ecological security through applied ecology / Daming He, Ruidong Wu, Yan Feng, Chengzhi Ding, Wenling Wang, D. W. Yu // Journal of applied ecology. - 2014. - № 51. - P. 1159-1168. 


\section{References}

1. Agreement on the cooperation for the sustainable development of the Mekong River basin 5 April 1995. Available at: http://www.mrcmekong.org/assets/Pub lications/agreements/95-agreement.pdf (accessed 05 September 2021).

2. Svensson J. China's water policy and the sharing of international rivers in Asia. Available at: http://www.globalwaterforum.org/2018/03/21/q-a-chinas-waterpolicy-and-the-sharing-of-international-rivers-in-asia/ (accessed 05 May 2021).

3. Borisova E. A. Transgranichnye reki v politike Kitaya [Transboundary rivers in China's policy]. Vostok - Orients, 2015, no. 2, pp. 121-131.

4. International hydropower association. Country profile. China. Available at: https://www.hydropower.org/country-profiles/china\#: :text=According\%20to\%20IHA's $\% 202020 \%$ 20Hydropower,at\%20up\%20to\%20600\%20GW (accessed 05 May 2021).

5. Bokeriya S., Nguyen Thi Ngoc Lan. Hydropower development in Mekong River basin. Asia and Africa today, 2019, no. 10, pp. 24-29.

6. Rysbekov Yu. Kh., Rysbekov A. Yu. Upravlenie vodnymi resursami v Kitae [Water Resources Management in China]. Tashkent, 2014. 80 p. (Informatsionnyi sbornik NITs MKVK [Information collection of SIC ICWC]; No. 41).

7. 1997 Convention on the Law of the Non-Navigational Uses of International Watercourses: Adopted by General Assembly Resolution 51/229 of May 21, 1997. Available at: https://www.un.org/ru/documents/decl_conv/conventions/watercrs.shtml (accessed 05 May 2021). (In Russian).

8. Menniken T. China's performance in international resource politics: lessons from the Mekong. Contemporary Southeast Asia, 2007, vol. 1 (29), pp. 97-120.

9. Devlaeminck D. J., Xisheng Huang. China and global water conventions in light of recent development: Time to take a second look. Review of European, comparative and environmental law, 2020, vol. 29 (3), pp. 395-405.

10. Rieu-Clarke A., Loures F. R. Still not in force: should states support the 1997 UN Watercourses Convention? Review of European Community \& International Environmental Law, 2009, vol. 18 (2), pp. 185-197.

11. Environmental protection law of the People's Republic of China. Adopted on December 26, 1989, revised on April 24, 2014. Available at: http://www.china.org.cn/eng lish/environment/34356.htm (accessed 05 May 2021).

12. Forestry law of the People's Republic of China. Adopted on September 20, 1984, amended on April 29, 1998. Available at: http://www.china.org.cn/english/en vironment/207457.htm (accessed 05 May 2021).

13. Law of the People's Republic of China on water and soil conservation. Adopted on June 29, 1991. Available at: http://www.china.org.cn/environment/200708/20/content_1034358.htm (accessed 05 May 2021). 
Нгуен Тхи Ким Ань. Позиция Китайской Народной Республики в отношении использования трансграничной реки Меконг: международно-правовой анализ

14. Law of the People's Republic of China on prevention and control water pollution. Adopted on May 11, 1984, amended on May 15, 1996. Available at: http:/www.china.org.cn/government/laws/2007-04/17/content_1207459.htm (accessed 05 May 2021).

15. Water law of the People's Republic of China. Adopted on January 21, 1998. Available at: http://www.china.org.cn/english/government/207454.htm (accessed 05 May 2021).

16. Ministry of Water Resources. Briefings on the opinions of the state council on implementing the strictest water resources management system. Available at: http://www.china.org.cn/china/2012-02/17/content_24664350.htm (accessed 05 May 2021).

17. Ministry of Water Resources, People's Republic of China. International cooperation on trans-boundary rivers between China and its neighbouring countries 2015. Available at: http://www.mwr.gov.cn/english/mainsubjects/201604/P0201604065137 98903048.pdf (accessed 05 May 2021).

18. Devlaeminck D. J. China's water sharing treaties - Reciprocity in practice. China water risk. 2019. Available at: https:/www.chinawaterrisk.org/opinions/chinaswater-sharing-treaties-reciprocity-in-practice/ (accessed 05 May 2021).

19. Solntsev A. M. Ot konflikta k sotrudnichestvu: rossiisko-kitaiskie otnosheniya v oblasti upravleniya vodnymi resursami [From conflict to cooperation: Russian-Chinese relations in water management]. Mezhdunarodnoe pravo - International Law, 2009, no. 1, pp. 246-261.

20. Lei Xie. Shaofeng Jia. China's international transboundary rivers: Politics, security and diplomacy of shared water resources. Routledge, 2017. 222 p. DOI: 4324/9781315537900.

21. Solntsev A. M. Problema ispol'zovaniya transgranichnykh rek V stranakh BRIKS [The problem of using transboundary rivers in the BRICS countries]. In: Pravovoe regulirovanie okhrany okruzhayushchei sredy v stranakh BRIKS: monografiya [Legal regulation of environmental protection in the BRICS countries: monograph]. Tyumen: Tyumen State University Publishing House, 2018, pp. 261-277.

22. Memorandum of Understanding between the Ministry of Water Resources, the Republic of India and the Ministry of Water Resources, the People's Republic of China upon Provision of Hydrological Information of the Yaluzangbu/Brahmaputra River in Flood Season by China to India. Available at: http://waterbeyondborders.net/wpcontent /uploads/2018/05/Indo-China-MOU-on-Brahmaputra.pdf (accessed 05 September 2021).

23. Memorandum of Understanding on Hydrological Data Sharing on River Sutlej / Langqen Zangbo. Available at: https://jalshakti-dowr.gov.in/international-cooperation/bi lateral-cooperation-with-neighbouring-countries/india-china-cooperation (accessed 05 September 2021). 
24. India-China cooperation. Available at: http://mowr.gov.in/internationalcooperation/bilateral-cooperation-with-neighbouring-countries/india-china-cooperation (accessed 05 May 2021).

25. Memorandum of Understanding between the Ministry of Water Resources, the Republic of India and the Ministry of Water Resources, the People's Republic of China upon Provision of Hydrological Information of the Yaluzangbu/Brahmaputra River in Flood Season by China to India. Available at: http://waterbeyondborders.net/wpcontent/uploads/2018/05/Indo-China-MOU-on-Brahmaputra.pdf (accessed 05 May 2021).

26. Chellaney B. China is stealthily waging a water war (January 12, 2018). Available at: https://www.theglobeandmail.com/opinion/china-is-stealthily-waging-a-waterwar/article37583969/ (accessed 05 May 2021).

27. Svinarchuk T. O. Transgranichnye reki Indii i Kitaya: problemy sovmestnogo ispol'zovaniya vod [Transboundary rivers of India and China: problems of joint use of waters]. In: Vodnye resursy Indii: ekonomicheskie, politicheskie, sotsial'nye aspekty: materialy nauchnoi konferentsii [Water resources of India: economic, political, social aspects: proceedings of a scientific conference]. Moscow: Institute of Oriental Studies RAS, 2015, pp. 260-280.

28. Mamchits R.V Tibete postroyat krupneishuyu v mire GES (Mart 13, 2021) [The world's largest hydroelectric power station will be built in Tibet (March 13, 2021)]. Available at: www.if24.ru/v-tibete-postroyat-krupnejshuyu-v-mire-ges/ (accessed 05 May 2021).

29. Zhang Hongzhou, Mingjiang Li. China and Transboundary water policies in Asia. Routledge, 2019. 242 p.

30. Kornfeld I. Mega-dams and indigenous human rights. Cheltenham, UK; Northampton, MA: Edward Elgar Publishing, 2020. 244 p.

31. Leksyutina Ya. «Dobrososedskaya diplomatiya» Kitaya v Vostochnoi Azii [«Good Neighborly Diplomacy» of China in East Asia]. Aziya i Afrika segodnya, 2017, no. 9 , pp. 12-18.

32. MRC and China renew pact on water data provision and other cooperation initiatives. Available at: http://www.mrcmekong.org/news-and-events/news/mrc-and-china-renewpact-on-water-data-provision-and-other-cooperation-initiatives/ (accessed 05 May 2021).

33. China to provide the Mekong River Commission with year-round water data. Available at: https://www.mrcmekong.org/news-and-events/news/china-to-provide-themekong-river-commission-with-year-round-water-data/ (accessed 05 May 2021).

34. Wouters P., Huiping Chen. China's «soft-path» to transboundary water cooperation examined in the light of two UN Global water conventions - Exploring the «Chinese way». Water law, 2013, № 22, pp. 229-247.

35. Sanya Declaration of the First Lancang-Mekong Cooperation (LMC) Leaders' Meeting. Available at: https://www.fmprc.gov.cn/mfa_eng/wjdt_665385/2649_66 5393/t1350039.shtml (accessed 05 May 2021). 
36. Lancang-Mekong Cooperation: MRC welcomes the New Initiative for Regional Cooperation by six countries in the Mekong River Basin. Available at: http://www.mrcmekong.org/news-and-events/news/lancang-mekong-cooperation-mrcwelcomes-the-new-initiative-for-regional-cooperation-by-six-countries-in-the-mekongriver-basin/ (accessed 05 May 2021).

37. Li Keqiang's address at the 1st Lancang-Mekong Cooperation Leaders' Meeting. Available at: http://www.lmcchina.org/eng/zywj_5/t1514128.htm (accessed 05 May 2021).

38. Pham Phan Long. China's strategy on Lancang-Mekong Cooperation. Viet Ecology Foundation. April 2016. Available at: https:/www.rfa.org/vietnamese/news/Rea dersOpinions/langcang-mekong-2016-pplong-04192016155259.html (accessed 05 May 2021).

39. Five-year plan of action on Lancang-Mekong Cooperation (2018-2022), adopted on 4th Lancang-Mekong cooperation mechanism foreign minister's meeting - «Enhancing partnership for shared prosperity" 12.2018. Available at: https://data.opendev elopmentmekong.net/dataset/five-year-plan-of-action-on-lancang-mekong-cooperation2018-2022/resource/2116a77e-e493-42dd-90cb-edce1d3693df?inner_span=True （accessed 05 May 2021).

40. Vientiane Declaration of the Third Mekong-Lancang Cooperation (MLC) Leaders' Meeting 24.08.2020. Available at: http://www.lmcchina.org/eng/zywj_5/t1809 002.htm (accessed 05 May 2021).

41. The Mekong Basin countries are strengthening partnerships. Available at: https://rg.ru/2020/08/26/strany-bassejna-reki-mekong-ukrepliaiut-partnerstvo.html (accessed 05 May 2021). (In Russian).

42. Kalinin V. A., Troshin A. A., Balashov V. V. Ekonomicheskie interesy kitaiskogo biznesa v Laose: novye tendentsii 2000-2010-kh gg. [Economic interests of Chinese business in Laos: New Trends in the 2000s - 2010 s]. Ekonomicheskie otnosheniya, 2017, no. 3 (4), pp. 296-304.

43. Daming He, Ruidong Wu, Yan Feng, Chengzhi Ding, Wenling Wang, D. W. Yu Review: China's transboundary waters: new paradigms for water and ecological security through applied ecology. Journal of Applied Ecology, 2014, no. 51, pp. 11591168 . 